\title{
Isoenzyme analysis of Arthrobotrys, a nematode-trapping fungus
}

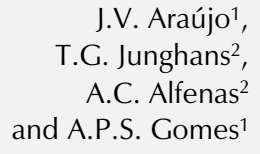

J.V. Araújo ${ }^{1}$,

T.G. Junghans ${ }^{2}$,

A.C. Alfenas ${ }^{2}$

and A.P.S. Gomes ${ }^{1}$

\author{
${ }^{1}$ Departamento de Veterinária and ${ }^{2}$ Departamento de Fitopatologia, \\ Bioagro, Universidade Federal de Viçosa, Viçosa, MG, Brasil
}

\section{Correspondence \\ J.V. Araújo \\ Departamento de Veterinária \\ Universidade Federal de Viçosa \\ 36571-000 Viçosa, MG \\ Brasil \\ Fax: 55 (031) 891-2317 \\ E-mail: jvictor@mail.ufv.br \\ Research supported by FINEP.}

Received February 28, 1997

Accepted July 28, 1997

\begin{abstract}
Extraction and isoenzyme analysis of four isolates of Arthrobotrys including A. musiformis, A. robusta and A. conoides were conducted. Among the 14 enzymes studied by starch gel electrophoresis, using morpholine-citrate as gel/electrode buffer, the following nine enzymes showed interpretable banding patterns: $\alpha$-esterase, fumarase, hexokinase, isocitrate dehydrogenase, leucine aminopeptidase, malate dehydrogenase, 6-phosphogluconate dehydrogenase, phosphoglucomutase and phosphoglucoisomerase. All isolates studied displayed typical isoenzyme phenotypes for each species. Two isolates of $A$. conoides differed in their $\alpha$-isoesterase banding patterns, but no differences were observed for the other enzymes. The assay was satisfactory for enzyme extraction and resolution of Arthrobotrys and could be used in future taxonomic and genetic studies of this organism.
\end{abstract}

Key words

- Nematophagous fungi

- Nematode-trapping fungus

- Predacious fungi

- Arthrobotrys

- Isoenzymes

- Electrophoresis
The fungi antagonistic to nematodes consist of a wide variety of organisms including nematode-trapping or predacious fungi, endoparasitic fungi, parasites of nematode eggs and cysts, and those producing nematotoxic metabolites. It is remarkable that fungi belonging to highly divergent orders and families occur in each of the above groups. Predacious, parasitic and biochemical relationships with nematodes have evolved among almost all major groups of soil fungi, ranging from Phycomycetes to Basidiomycetes (1). The genus Arthrobotrys currently presents 27 species and belongs to the group of nematode-predacious fungi (2). These fungi are relatively easy to culture on artificial media and numerous isolates are currently maintained in various laboratories worldwide. The identification of Arthrobotrys spp is based on morphological characteristics mainly following the keys of Cooke and Godfrey (3) and Van Oorschot (2). The teleomorph of most Arthrobotrys species is presently unknown and identification is mainly based on conidial size, morphology of conidiophores and trapping organs of the anamorph. However, in some cases the morphological features of the anamorph alone do not allow correct species identification (4). In this case, one may use molecular markers to establish taxonomic relationships among isolates. Isoenzyme analysis has proved to be a powerful tool in taxonomy and genetics of fungi $(5,6)$. In the present study we describe the techniques for protein extraction and starch gel isoenzyme electrophoresis for three Arthrobotrys species used in previous studies (7-9) to investigate their 
predacious ability on animal and plant parasite nematodes.

The following four isolates of Arthrobotrys grown on nematode larvae collected in different regions of Brazil were isolated according to Santos et al. (10) and stored on $2 \%$ potato-dextrose-agar at $4{ }^{\circ} \mathrm{C}:$ A. musiformis (Figure 1, lane A), A. conoides (Figure 1, lanes B and D), and A. robusta (Figure 1, lane $C)$. The cultures were identified according to the keys of Cooke and Godfrey (3) and Van Oorschot (2). Two single-conidial cultures of each isolate were obtained and compared to the respective original culture. Enzyme extraction was performed from mycelium grown in liquid medium (11). After 7 days of incubation at $25^{\circ} \mathrm{C}$ in the dark, the cultures were filtered through a Buchner funnel containing Whatman No. 1 filter paper. The mycelium cake was washed three times with distilled water, excess moisture was removed by blotting the mycelium on filter paper and $400 \mathrm{mg}$ of each sample was crushed with an ice-cold mortar and pestle containing $1 \mathrm{ml}$ ice-cold extraction buffer of the following composition: $0.34 \mathrm{M}$ dibasic sodium phosphate, $0.2 \mathrm{M}$ sucrose, $2.56 \%$ polyvinylpyrrolidone- $40,5.7 \mathrm{mM}$ L-ascorbic acid, $5.8 \mathrm{mM}$ sodium diethyldithiocarbamate, $2.6 \mathrm{mM}$ sodium bisulfate, $2.5 \mathrm{mM}$ sodium borate, $0.2 \%$ ß-mercaptoethanol, and $1 \%$ polyethylene glycol 6000 (6). During homogenization, small quantities of polyvinylpolypyrrolidone were added to the sample. The homogenate was adsorbed onto 12 x 5 mm chromatographic Whatman No. 3 paper wicks and stored in microcentrifuge tubes at $-85^{\circ} \mathrm{C}$ until the time for electrophoresis.

Electrophoresis was performed on $13 \%$ hydrolyzed starch gels containing 3\% sucrose and $2 \mathrm{mM}$ morpholine-citrate, $\mathrm{pH}$ 7.1, diluted 1:20, as gel buffer and $40 \mathrm{mM}$ morpholine-citrate, $\mathrm{pH}$ 6.1, in the electrode compartments. After electrophoresis, the gels
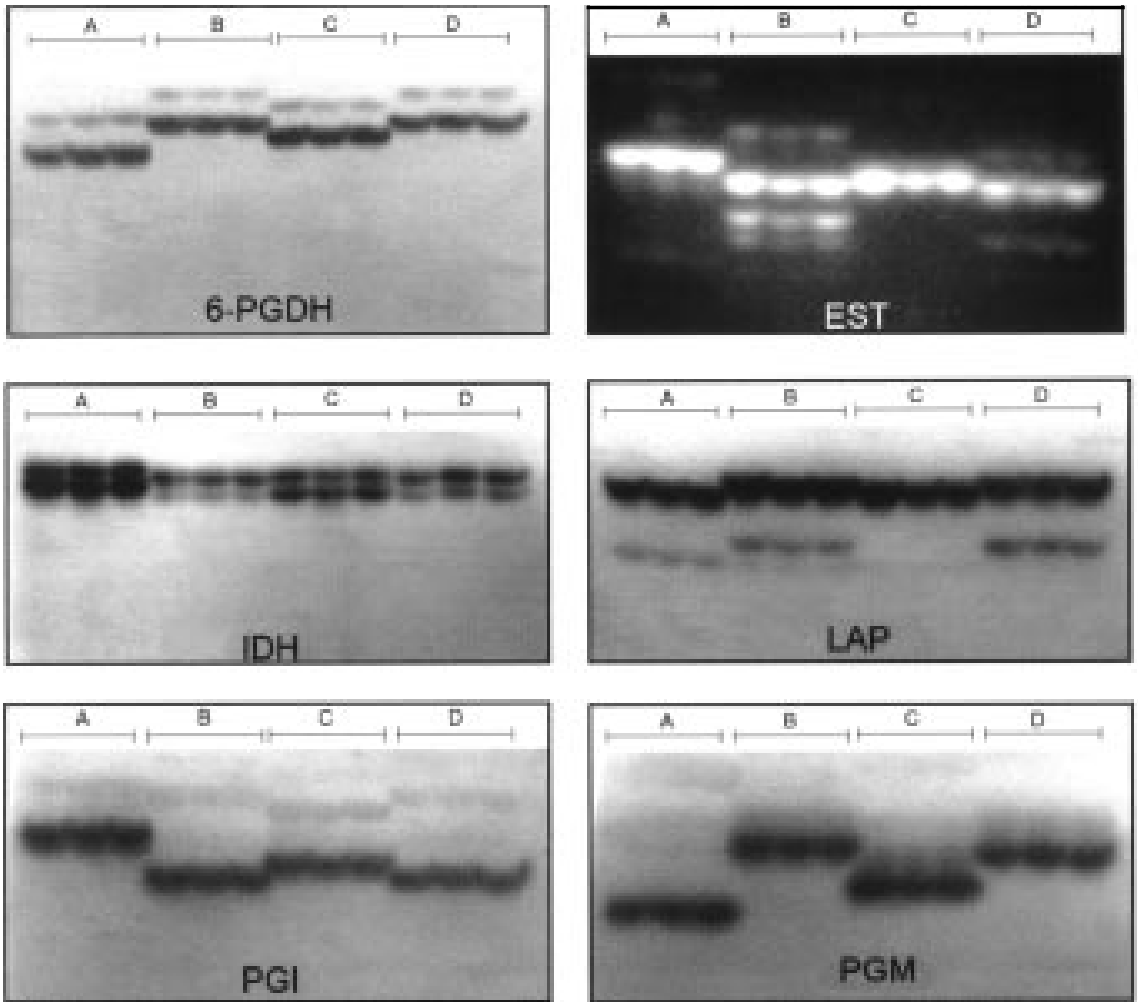
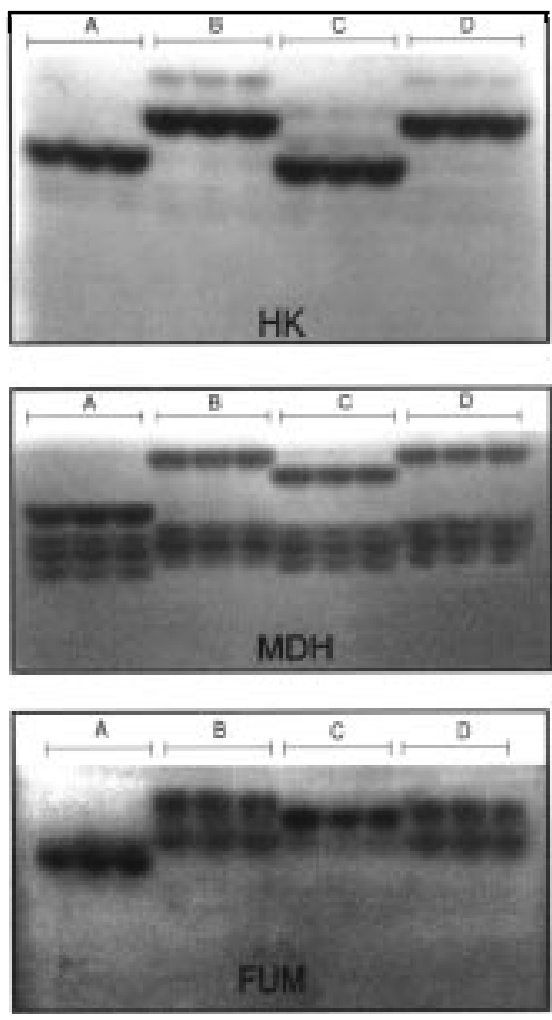

Figure 1 - Isoenzyme phenotypes of Arthrobotrys isolates. Lane A, A. musiformis; Lane B, A. conoides; Lane C, A. robusta; Lane D, A. conoides. The original and two monoconidial cultures are shown from left to right for each isolate. For enzyme abbreviations, see text. 
were stained for the following enzyme activities (12): acid phosphatase (ACP, EC 3.1.3.2), aconitase (ACO, EC 4.2.1.3), diaphorase (DIA, EC 1.8.1.4), $\alpha$-esterase $(\alpha$ EST, EC 3.1.1.1), fumarase (FUM, EC 4.2.1.2), glutamate dehydrogenase (GDH, EC 1.4.1.3), hexokinase (HK, EC 2.7.1.1), isocitrate dehydrogenase (IDH, EC 1.1.1.42), leucine aminopeptidase (LAP, EC 3.4.11.1), malate dehydrogenase (MDH, EC 1.1.1.37), 6-phosphogluconate dehydrogenase (6PGDH, EC 1.1.1.44), phosphoglucoisomerase (PGI, EC 5.3.1.9), phosphoglucomutase (PGM, EC 2.7.5.1) and superoxide dismutase (SOD, EC 1.15.1.1).

The extraction method and buffer systems used for electrophoresis were suitable for 9 ( $\alpha$-EST, FUM, HK, IDH, LAP, MDH, 6-PGDH, PGM and PGI) of the 14 enzymes tested. These enzymes exhibited good activity and resolution and were all polymorphic, displaying typical isoenzyme phenotypes for each species, with the exception of IDH which was monomorphic for all isolates studied (Figure 1). Fumarase exhibited low enzyme activity, but scorable banding patterns. $\mathrm{MDH}$, IDH, LAP and 6-PGDH showed up two zones of activity whereas $\alpha$-EST, FUM, HK, PGI and PGM showed a single locus. Enzyme activity was not detected for ACP, ACO, DIA, GDH or SOD. The two isolates of $A$. conoides studied differed in their isoesterase profiles but no differences were observed for the other enzymes. Mankau (1) collected approximately 50 isolates of $A$. conoides and most of these isolates were unique and could be separated from the others on the basis of some physiological, morphological, ecological or biochemical characteristics. The isolates exhibited different patterns of sporulation and chlamydospore production, different responses and growth rates on a variety of comparative media, and different degrees of predaciousness or response to trap-stimulatory factors. In the present study, the original cultures displayed a pattern similar to that of the monoconidial culture of each isolate for all enzymes tested. Although we only studied two single spore cultures, we did not expect variability between them, since the original culture was obtained from the same conidiophore. However, analysis of several monoconidial isolates from different sources and geographic origins would be valuable to estimate the genetic variability of the fungal population.

The extraction buffer seems to affect enzyme stability. R.D. Lima (unpublished results), working in our laboratory with several species of Arthrobotrys, including A. conoides, A. musiformis, and A. robusta, did not obtain satisfactory results on starch or polyacrylamide gels when Tris- $\mathrm{HCl}(0.62$ $\mathrm{M}, \mathrm{pH}$ 6.8) was used as extraction buffer. Later, Lima (13) obtained satisfactory results using our technique and 29 isolates of Arthrobotrys spp exhibited 52 isoenzyme phenotypes.

The isoenzyme systems studied are potentially important for future studies involving the taxonomy and genetics of Arthrobotrys spp.

\section{Acknowledgments}

The authors wish to thank Rosangela D'arc de Lima, Departamento de Fitopatologia, Universidade Federal de Viçosa, Brazil, for valuable comments and advice about this manuscript. 


\section{References}

1. Mankau R (1980). Biological control of nematode pests by natural enemies. Annual Review of Phytopathology, 18: 415440.

2. Van Oorschot CAN (1985). Taxonomy of the Dactylaria complex. V. A review of Arthrobotrys and allied genera. Studies in Mycology, 26: 61-96.

3. Cooke RC \& Godfrey BES (1964). A key of nematode-destroying fungi. Transactions of the British Mycological Society, 47: 6174.

4. Gray NF (1988). Fungi attacking vermiform nematodes. In: Poinar Jr GO \& Jansson HB (Editors), Diseases of Nematodes. Vol. II. CRC Press, Boca Raton.

5. Micales JA, Bonde MR \& Peterson GL (1986). The use of isozyme analysis in fungal taxonomy and genetics. Mycotaxon, 27: 405-409.
6. Alfenas AC, Peters I, Brune W \& Passador GC (1991). Eletroforese de Proteínas e Isoenzimas de Fungos e Essências Florestais. 1st edn. SIF, Viçosa.

7. Araujo JV, Santos MA, Ferraz S \& Maia AS (1993). Antagonistic effect of predacious Arthrobotrys fungi on infective Haemonchus placei larvae. Journal of Helminthology, 67: 136-138.

8. Araujo JV, Santos MA, Ferraz S \& Maia AS (1994). Biological control "in vitro" of infective Haemonchus placei larvae by predacious fungi Arthrobotrys musiformis. Arquivo Brasileiro de Medicina Veterinária e Zootecnia, 46: 194-204.

9. Santos MA, Ferraz S \& Muchovej JJ (1992). Evaluation of twenty species of fungi from Brazil for biocontrol of Meloidogyne incognita Race III. Nematropica, 22: 183-192.
10. Santos MA, Ferraz S \& Muchovej JJ (1991). Detection and ecology of nematophagous fungi from Brazilian soils. Nematologia Brasileira, 15: 121-134.

11. Kado Cl \& Hesket MG (1970). Selective media for isolation of Agrobacterium, Corynebacterium, Erwinia, Pseudomonas and Xanthomonas. Phytopathology, 60: 969-976.

12. Vallejos CE (1983). Enzyme activity staining. In: Tanksley SD \& Orton TJ (Editors), Isozyme in Plant Genetics and Breeding. Elsevier Publishing, New York.

13. Lima RD (1996). Characterization of the isolates and evaluation of the pathogenicity of Arthrobotrys spp. to phytonematodes. Universidade Federal de Viçosa, Doctoral thesis, Viçosa, MG, Brazil. 